\title{
Olfactory Receptor Proteins in Axonal Processes of Chemosensory Neurons
}

\author{
Joerg Strotmann, Olga Levai, Joerg Fleischer, Karin Schwarzenbacher, and Heinz Breer \\ Institute of Physiology, University of Hohenheim, 70593 Stuttgart, Germany
}

Olfactory receptors are supposed to act not only as molecular sensors for odorants but also as cell recognition molecules guiding the axons of olfactory neurons to their appropriate glomerulus in the olfactory bulb. This concept implies that olfactory receptor proteins are located in sensory cilia and in the axons. To approach this critical issue, antibodies were generated against two peptides, one derived from olfactory receptor m0R256-17, one derived from the "m0R37" subfamily. By means of immunohistochemistry and double-labeling studies using transgenic mouse lines as well as Western blot analyses, it was demonstrated that the newly generated antibodies specifically recognized the receptor proteins. To scrutinize the hypothesis that olfactory receptor proteins may also be present in the axonal processes and the nerve terminals, serial sections through the olfactory bulb were probed with the antibodies. Two glomeruli in each bulb were stained by anti-m0R256 - 17, one positioned in the medial, one in the lateral hemisphere. Fiber bundles approaching the glomeruli through the outer nerve layer also displayed intense immunofluorescence. A similar picture emerged for the antibody anti-m0R37, a small number of glomeruli in the ventral domain of the bulb was stained. On serial sections through the olfactory bulb of m0R37transgenic mouse lines, double-labeling experiments demonstrated that distinct immunoreactive glomeruli corresponded to glomeruli that were targeted by neurons expressing a particular member of the m0R37 receptor subfamily. These data indicate that olfactory receptor (OR) proteins are indeed present in the axonal processes and nerve terminals of olfactory sensory neurons, thus supporting the notion that ORs may participate in the molecular processes underlying the fasciculation and targeting of olfactory axons.

Key words: olfactory receptor; axon guidance; antibody; olfactory bulb; projection; transgenic mouse

\section{Introduction}

The projection patterns of olfactory sensory neurons (OSNs) are supposed to provide the basis for encoding the quality of a chemosensory stimulus in a topographic map of activity in the olfactory bulb (for review, see Buck, 1996, 2000; Mori et al., 1999; Bozza and Mombaerts, 2001; Mombaerts, 2004). Although neurons expressing a given olfactory receptor (OR) gene appear to be randomly dispersed within one of the four epithelial expression zones (Ressler et al., 1993; Vassar et al., 1993; Strotmann et al., 1994b), their axonal projections converge onto one medial and one lateral glomerulus in the olfactory bulb. This convergence, initially observed by in situ hybridization that detected receptor mRNA in the axon terminals (Ressler et al., 1994; Vassar et al., 1994), was subsequently clearly documented by means of genetically manipulated mice that generated a bicistronic mRNA encoding the OR as well as a marker protein. This approach made it possible to selectively visualize the axons and nerve terminals of all cells expressing the same OR (Mombaerts et al., 1996; Wang et al., 1998; Strotmann et al., 2000; Zheng et al., 2000; Potter et al., 2001). Several lines of evidence suggest that the OR proteins may be directly or indirectly involved in convergent axon projection and glomerulus formation. It was found in transgenic mice that

\footnotetext{
Received June 30, 2004; accepted July 21, 2004.

This work was supported by the Deutsche Forschungsgemeinschaft, Sonderforschungsbereich 495, and the Leibniz Program. We thank Kerstin Bach and Olaf Selchow for excellent technical assistance.

Correspondence should be addressed to Dr. Heinz Breer at the above address. E-mail: breer@uni-hohenheim.de. D0I:10.1523/JNEUROSCI.2588-04.2004

Copyright $\odot 2004$ Society for Neuroscience $\quad 0270-6474 / 04 / 247754-08 \$ 15.00 / 0$
}

cells with the coding region for one OR gene replaced by that of another redirected their axons to a location expected for the introduced receptor (Mombaerts et al., 1996; Wang et al., 1998; Bozza et al., 2002). Moreover, deletion of one particular OR gene coding region destroyed glomerular convergence (Wang et al., 1998); in more recent studies it was found that genetic disruption of one OR gene permitted the expression of other ORs in that particular neuron population and these cells did not converge any longer, but targeted multiple glomeruli, apparently directed by the novel OR they expressed (Serizawa et al., 2003; Lewcock and Reed, 2004). Thus, the OR protein seems to be critical for axon sorting, converging, and targeting. The tight linkage between the choice of a receptor type and the site of axonal convergence in the bulb raised the possibility that in OSNs, receptor proteins may fulfill two distinct roles; in the cilia recognizing odorous molecules from the environment and in the axons recognizing molecular cues in the olfactory bulb.

The question whether OR proteins are indeed present in the axons and nerve terminals of OSNs is thus of fundamental importance toward an understanding of the functional wiring in the olfactory system. In this study, antibodies were generated against unique epitopes of distinct OR types and used in immunohistochemical experiments to visualize the receptor proteins in wholemount preparations and tissue sections of the olfactory system.

\section{Materials and Methods}

Animals and tissue preparation. Wild-type C57/BL6 mice were obtained from Charles River (Sulzfeld, Germany). Transgenic mice from the lines mOR37A-green fluorescent protein (GFP), mOR37-B-lacZ and 

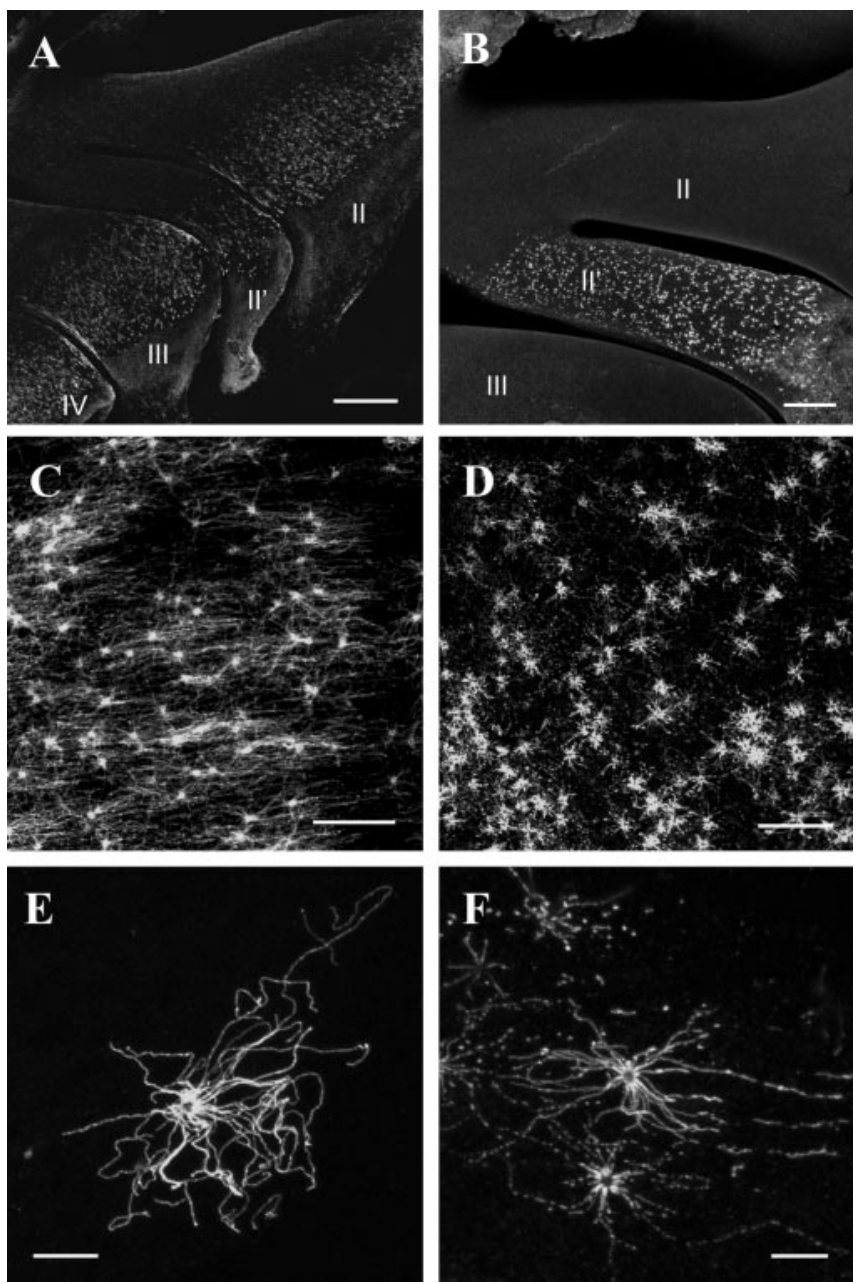

Figure 1. $A, B$, View onto the whole-mount nasal turbinates probed with anti-m0R256-17 antibody $(A)$ or anti-m0R37 antibody $(B)$, respectively. II-IV, Endoturbinates. Scale bars: (in A) $500 \mu \mathrm{m}$; (in B) $200 \mu \mathrm{m}$. C, D, View onto the medial surface of endoturbinate ll after incubation of anti-m0R256-17 antibody ( $($ ) or anti-m0R37 antibody (D). The knobs and cilia of distinct OSNs are strongly immunoreactive. Scale bars, $40 \mu \mathrm{m}$. E, F, High magnification of anti-m0R256-17-immunoreactive $(E)$ or anti-mOR37-immunoreactive $(F)$ OSN; the olfactory knob and cilia radiating in all directions are fluorescent. Scale bars, $10 \mu \mathrm{m}$.

mOR37-C-lacZ (Strotmann et al., 2000) were kept at the University of Hohenheim transgenic core facility; housing conditions fulfilled the animal welfare guidelines. Timed pregnant mice were obtained by $2 \mathrm{hr}$ mating period and subsequent vaginal plug inspection. For dissection, animals were deeply anesthetized with $\mathrm{CO}_{2}$ and decapitated. All experiments comply with the Principles of Animal Care of the National Institutes of Health, publication number 85-23, revised in 1985, and with the current laws of Germany.

Generation of sequence-specific antibodies. The peptides (LKNLWGPDKTISYGG), located in the first putative extracellular loop of mOR256-17, and (GKPKSKDPLGADKQD) located in the third putative extracellular loop of the mOR37 subtypes mOR37A-E (Hoppe et al., 2000), were synthesized and conjugated to KLH (Squarix Biotechnology, Marl, Germany). Rabbits were immunized according to standard procedures (Charles River Laboratories, Kisslegg, Germany). After final bleeding, antibodies were purified by peptide-affinity chromatography (Squarix Biotechnology).

Isolation of sensory cilia from mouse olfactory epithelium. Olfactory cilia were isolated using the calcium shock method according to Anholt et al. (1986). Briefly, the olfactory epithelium was dissected from mouse nasal turbinates and washed in cold Ringer's solution (in mM: $120 \mathrm{NaCl}, 5 \mathrm{KCl}$, $1.6 \mathrm{~K}_{2} \mathrm{HPO}_{4}, 1.2 \mathrm{MgSO}_{4}, 25 \mathrm{NaHCO}_{3}$, and 7.5 D-glucose, $\mathrm{pH}$ 7.4). The tissue was gently stirred for $5 \mathrm{~min}$ at $4^{\circ} \mathrm{C}$ in Ringer's solution supplemented with $10 \mathrm{mM} \mathrm{CaCl}_{2}$. Detached cilia were separated by centrifuga- tion at $4000 \times g$ and $4^{\circ} \mathrm{C}$ for $5 \mathrm{~min}$. The supernatant was collected, and the pellet was resuspended in Ringer's solution containing $10 \mathrm{mM} \mathrm{CaCl}_{2}$ and centrifuged as described above. The supernatants were combined and centrifuged at $19,000 \times g$ and $4^{\circ} \mathrm{C}$ for $15 \mathrm{~min}$. The resulting pellet containing the cilia was resuspended in a small volume of MES buffer (in mM: 10 Tris, $3 \mathrm{MgCl}_{2}$, and $2 \mathrm{EGTA}, \mathrm{pH}$ 7.4), frozen in liquid nitrogen and stored at $-70^{\circ} \mathrm{C}$.

Preparation of a ciliary membrane fraction. Olfactory cilia resuspended in MES buffer were centrifuged at $15,000 \times g$ and $4^{\circ} \mathrm{C}$ for $30 \mathrm{~min}$. The pellet was resuspended in $5 \mathrm{~mm}$ Tris, $\mathrm{pH}$ 7.5. After $30 \mathrm{~min}$ on ice, followed by centrifugation at $15,000 \times g$ and $4^{\circ} \mathrm{C}$ for $30 \mathrm{~min}$, the pellet was resuspended in $5 \mathrm{~mm}$ Tris, $\mathrm{pH}$ 7.5. Protein concentrations were determined by standard procedures (Bradford, 1976).

SDS-PAGE and Western blot analysis (immunoblotting). Ten micrograms of the ciliary membrane fraction were supplemented with electrophoresis buffer (7.5 mm DTT, 2.5\% SDS, $45 \%$ glycerol, and $0.3 \mathrm{~m}$ Tris, $\mathrm{pH}$ $6.8,0.045 \%$ bromphenol blue), boiled for $3 \mathrm{~min}$, separated by SDS PAGE, and transferred to nitrocellulose membranes using standard protocols. For Western blot analysis, nonspecific binding sites were blocked with $5 \%$ milk powder in TBST ( $10 \mathrm{~mm}$ Tris, $\mathrm{pH} 7.4,150 \mathrm{~mm} \mathrm{NaCl}$, and $0.05 \%$ Tween 20$)$ and probed with the primary antibody $\left(4.76 \times 10^{-4}\right.$ $\mu \mathrm{g} / \mu \mathrm{l}$ ) in TBST with $2.5 \%$ milk powder [the rabbit anti-G $\alpha_{\mathrm{s} / \mathrm{olf}}$ antibody used for the loading control was purchased from Santa Cruz Biotechnology (Santa Cruz, CA) and diluted 1:1500]. To test the specificity of antimOR37, the antibody was preincubated with a fivefold excess of the corresponding blocking peptide. The secondary antibody (anti-rabbitperoxidase; Bio-Rad, Hercules, CA) was diluted in $2.5 \%$ milk powder in TBST and detected using the ECL system (Amersham Biosciences, Arlington Heights, IL).

Immunohistochemistry on tissue sections. For immunohistochemistry on nasal epithelium, the bones covering the lateral nasal walls of adult animals were carefully removed using a bone cutter. Heads from postnatal day 6 and embryonic animals were entirely processed after removal of the lower jaw. Olfactory bulbs from adult animals were carefully removed from the cranium. The specimens were then either fixed for 50 min (adult animals) or $4 \mathrm{hr}$ (embryos) on ice in $4 \%$ paraformaldehyde for anti-mOR256-17 or $30 \mathrm{~min}$ in $4 \%$ paraformaldehyde on ice for anti-mOR37 (postnatal day 6 animals). Before sectioning, the specimen were incubated in $25 \%$ sucrose overnight. Subsequently, $16-20 \mu \mathrm{m} \mathrm{sec}-$ tions were generated using a Leica (Nussloch, Germany) CM3500 cryostat at $-20^{\circ} \mathrm{C}$ and transferred to Superfrost slides (Menzel). Immunohistochemical stainings were performed with anti-mOR256-17 $(1.5 \times$ $\left.10^{-3} \mu \mathrm{g} / \mu \mathrm{l}\right)$ in PBS containing 10\% normal goat serum (NGS), $0.3 \%$ Triton X-100 overnight at $4^{\circ} \mathrm{C}$, or with anti-mOR37 $\left(1.48 \times 10^{-3} \mu \mathrm{g} / \mu \mathrm{l}\right)$ in PBS containing $10 \%$ NGS and $0.1 \%$ Triton X-100 at $4^{\circ} \mathrm{C}$ overnight. After washing in PBS, the sections were incubated with anti-rabbit Alexa488 (Molecular Probes Europe BV, Leiden, Netherlands) for $2 \mathrm{hr}$ at room temperature.

For double-labeling experiments with anti-mOR37 in the mOR37transgenic mouse lines (Strotmann et al., 2000), the following antibodies were combined with anti-mOR37 under the conditions described above: 1:500 diluted anti-rabbit Cy3 to detect anti-mOR37 in line mOR37AGFP; 1:500 diluted anti- $\beta$-galactosidase (monoclonal; Promega, Mannheim, Germany), visualized by 1:500 diluted anti-mouse Alexa 568 (Molecular Probes) for lines mOR37B-lacZ and mOR37C-lacZ. Finally the sections were mounted in Slow Fade (antifade kit containing DAPI; Molecular Probes). Control experiments were performed by preincubation for $30 \mathrm{~min}$ of anti-mOR256-17 or anti-mOR37 with the respective peptide used for immunization (fivefold excess of peptide).

Whole-mount immunohistochemistry. For whole-mount immunostainings, essentially the same procedures as described for sections were performed, except that all specimens were fixed for $4 \mathrm{hr}$ on ice.

In situ hybridization. The biotin-labeled antisense riboprobe was generated from partial cDNA clones in pGem-T plasmids encoding the Mus musculus mOR256-17 (AY073576, 1-925) using the T7/SP6 RNA transcription system (Roche Diagnostics, Mannheim, Germany) as recommended by the manufacturer. After fixation in $4 \%$ paraformaldehyde and $0.1 \mathrm{M} \mathrm{NaHCO}_{3}, \mathrm{pH} 9.5$, for $30 \mathrm{~min}$ at $4^{\circ} \mathrm{C}$, slices were washed in $1 \times$ PBS for $1 \mathrm{~min}$, then incubated in $0.2 \mathrm{M} \mathrm{HCl}$ for $10 \mathrm{~min}$, in $1 \%$ Triton X-100 
and $1 \times$ PBS for $2 \mathrm{~min}$, and again washed twice in $1 \times$ PBS for $30 \mathrm{sec}$. Finally, sections were incubated in $50 \%$ formamide and $5 \times$ SSC $(1 \times$ SSC: $0.15 \mathrm{M} \mathrm{NaCl}$ and $0.015 \mathrm{M} \mathrm{Na}$-citrate, $\mathrm{pH} 7.0$ ) for 10 $\mathrm{min}$. Then tissue was hybridized in hybridization buffer (50\% formamide, $2 \times$ SSC, $10 \%$ dextran sulfate, $20 \mu \mathrm{g} / \mathrm{ml}$ yeast tRNA, and $0.2 \mathrm{mg} / \mathrm{ml}$ herring sperm DNA) containing the probe and incubated in a humid box ( $50 \%$ formamide) at $55^{\circ} \mathrm{C}$ overnight.

After slides were washed twice in $0.1 \times$ SSC for $30 \mathrm{~min}$ at $60^{\circ} \mathrm{C}$, they were treated with $1 \%$ blocking reagent (Roche Diagnostics) in TBS (100 mu Tris, pH 7.5, $150 \mathrm{~mm} \mathrm{NaCl}$ ) with $0.3 \%$ Triton X-100 for $30 \mathrm{~min}$ at room temperature. Hybridization signals were visualized using the TSA kit (PerkinElmer Life Sciences, Boston, MA). Sections were mounted in Slow Fade.

Microscopy and photography. Whole-mount specimens and sections were photographed either using a confocal laser-scanning microscope (LSM 510 META; Zeiss, Oberkochen, Germany) or a Zeiss Axiophot equipped with epifluorescence and a SensiCam digital camera (Zeiss). Pictures were transferred to Adobe Photoshop to adjust brightness and contrast.

\section{Results}

As a first approach to assess the ability of peptide-derived antibodies to recognize the corresponding receptor proteins, whole-mount preparations of intact nasal turbinates from adult C57/BL6 mice were analyzed. Figure $1 A$ shows a view onto the surface of the turbinates after incubation with the $\alpha$-mOR256-17 antibody. A punctate staining pattern emerged on each of the turbinates, however, immunoreactivity was not observed on the entire structures, but was restricted to a well circumscribed band extending in anterior-to-posterior direction, related to the medial expression zone. In previous in situ hybridization studies we have demonstrated that mOR256-17 is expressed in OSNs located in the medial zone of the olfactory epithelium (Kaluza et al., 2004). The pattern of immunoreactivity thus exactly matched the pattern obtained by in situ hybridizations. In contrast to the zonally distributed mOR256-17-expressing cells, neurons that express a member of the $m O R 37$ subfamily are found clustered in the central region of the turbinates (Strotmann et al., 1992, 1994a). Incubation of whole-mount nasal preparations with the $\alpha$-mOR37 antibody resulted in immunoreactivity exclusively in the central region of endoturbinate II, whereas all other turbinates showed no staining (Fig. $1 B)$. Thus, also the pattern of anti-mOR37 immunoreactivity was identical to the distribution pattern obtained by in situ hybridization with mOR37-specific riboprobes (Strotmann et al., 2000). In control experiments using antibodies preincubated with the corresponding peptides, no immunoreactivity was detectable (data not shown). Both antibodies thus generated staining patterns that matched the characteristic spatial distribution of cells that express the corresponding receptor type.

To further evaluate whether the antibodies indeed label OSNs expressing the respective ORs, the whole-mount specimens were examined at higher magnification. Figure 1, $C$ and $D$, shows representative examples of immunoreactive regions for the two re spective antibodies. In both cases, bright immunofluorescence
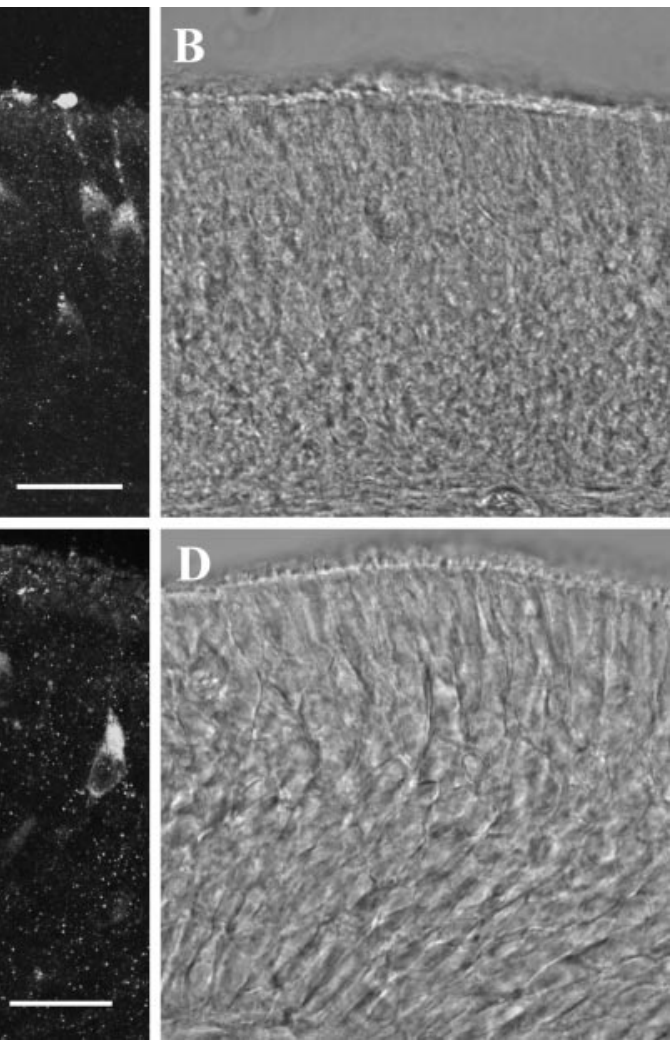

Figure 2. A, Confocal image ( $16.8 \mu \mathrm{m}$ stack) of a cross section through the olfactory epithelium of a mouse probed with the olfactory epithelium probed with the anti-m0R37 antibody. A group of brightly immunoreactive OSNs is visible positioned in

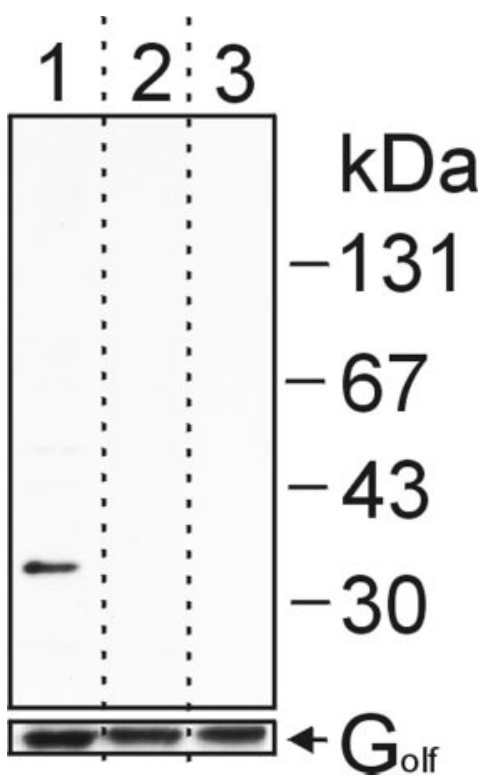

Figure 3. Western blot analysis using anti-m0R37 antibody. We loaded $10 \mu \mathrm{g}$ of a ciliary membrane fraction prepared from mouse olfactory cilia on each lane of a polyacrylamide gel, subjected to SDS-PAGE, and transferred to a nitrocellulose membrane. After blotting, the lanes were separated (as indicated by dotted lines) and incubated with either anti-m0R37 (top panel, lane 1), anti-m0R37 preabsorbed to the corresponding antigenic blocking peptide (lane 2), or without primary antibody (lane 3). As a loading control, the same blot was reprobed with anti- $\mathrm{G}_{\mathrm{s} / \mathrm{olf}}$ antibody (bottom panel). Molecular weight markers are indicated. 


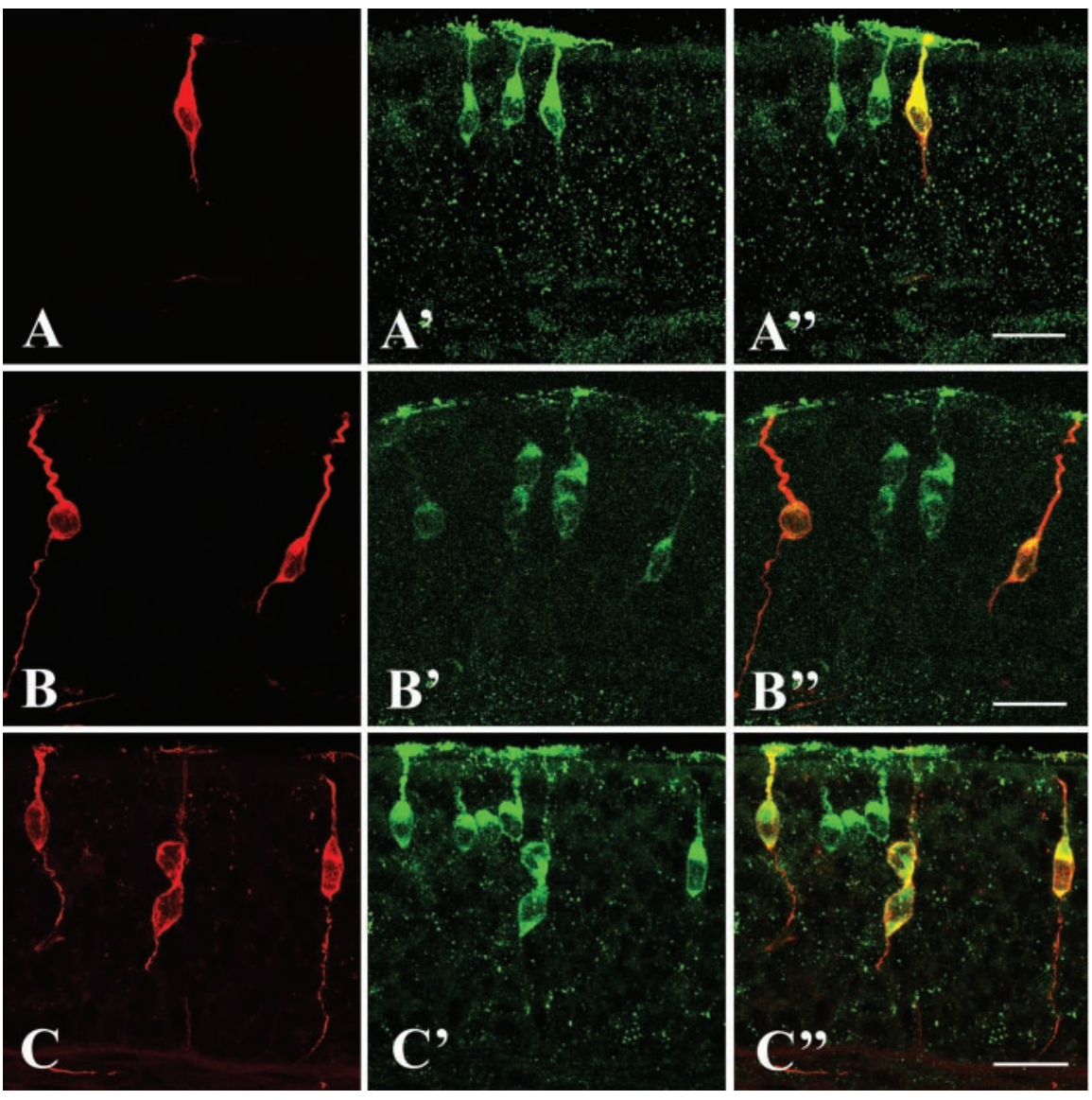

Figure 4. $A-A^{\prime \prime}$, Cross section through the olfactory epithelium of an m0R37A-GFP transgenic mouse. Expression of $m 0 R 37 A$ is visualized by intrinsic GFP fluorescence $(A)$. Double labeling with the anti-m0R37 antibody visualized by an Alexa-568-labeled secondary antibody $\left(A^{\prime}\right)$. Overlay of both pictures $\left(A^{\prime \prime}\right)$ shows that all m0R37A-expressing cells are immunoreactive for the anti-m0R37 antibody. Scale bar, $20 \mu \mathrm{m}$. $B, B^{\prime \prime}$, Cross section through the olfactory epithelium of an m0R37B-lacZ transgenic mouse probed with anti- $\beta$-galactosidase and Alexa-568-labeled secondary antibody to visualize m0R37B expression $(B)$, and simultaneously with the anti-m0R37 antibody visualized by an Alexa-488-labeled secondary antibody $\left(B^{\prime}\right)$. Overlay of both pictures $\left(B^{\prime \prime}\right)$ shows that all mOR37B-expressing cells visualized by lacZ expression are immunoreactive for the anti-m0R37 antibody. Scale bar, $20 \mu \mathrm{m}$. $C-C^{\prime \prime}$, Cross section through the olfactory epithelium of an m0R37C-lacZ transgenic mouse probed with anti- $\beta$-galactosidase and Alexa-568-labeled secondary antibody $(C)$, and simultaneously with anti-m0R37 antibody visualized by an Alexa-488-labeled secondary antibody $\left(C^{\prime}\right)$. Overlay of both pictures $\left(C^{\prime \prime}\right)$ shows that all m0R37C-expressing cells visualized by lacZ expression are immunoreactive for the anti-m0R37 antibody. Scale bar, $20 \mu \mathrm{m}$.

was visible in dot-like structures scattered throughout the surface of the epithelium; these appeared like the knobs of individual OSNs. In addition, a more diffuse staining was detectable between these structures covering the surface of the epithelium, possibly corresponding to the cilia of distinct OSNs. Indeed, at even higher magnification (Fig. $1 E, F$ ), a number of strongly immunoreactive cilia radiating in all directions from a central structure became visible. The length of individual cilia was determined to reach up to $60 \mu \mathrm{m}$. Interestingly, each knob displayed a ringshaped fluorescence with a dark center. Together these data indicate that the newly generated antibodies specifically stain the cellular compartments that are supposed to contain the highest concentration of OR proteins.

Although, the whole-mount immunohistochemical stainings provided a clear view of the spatial patterns of immunoreactive OSNs and their chemoreceptive structures on the surface of the epithelium, they did not permit an inspection of the entire cell within the depth of the epithelium to explore if the antibodies may recognize the receptor protein also in other cell compartments. Therefore, in a next approach cross sections through the olfactory epithelium were analyzed. Figure 2, $A$ and $C$, shows representative results. After incubation with the anti-mOR256-17 antibody (Fig. $2 A$ ), a few distinct OSNs were stained, whereas the majority of cells were not reactive. The strongest immunoreactivity was detectable in the knob and cilia of each cell that formed a brush-like structure on the surface of the epithelium. Interestingly, rather intense immunoreactivity was also observed along the dendritic process and within the soma of individual OSNs. The staining along the dendrite typically appeared in a dot-like manner; also the soma of most cells was not homogeneously stained, but revealed a stronger supranuclear staining (arrow). The somata of most antimOR256-17-reactive OSNs were positioned in a similar horizontal layer of the epithelium. In a few cases we observed immunoreactivity also at the basal pole of the OSNs, where the axonal process extends into the deeper layer of the epithelium (arrowhead). No staining could ever be observed in other cell types of the epithelium, like basal or sustentacular cells.

Using the anti-mOR37 antibody, a similar picture of cellular staining emerged (Fig. 2C); however, in contrast to antimOR256-17, the stained cells were more densely packed and positioned throughout all laminar layers of the epithelium. For both antibodies, preincubation with an excess amount of the peptide used for immunization completely abolished the staining (data not shown).

The results described so far strongly suggested that the two antibodies recognized the corresponding receptor proteins in the appropriate OSNs. To further substantiate this notion, biochemical experiments were performed. As one criterion to ascertain the interaction of the antibodies with their respective OR antigens, Western blot analyses were performed. In immunoblotting experiments using a membrane-enriched fraction from isolated olfactory cilia, the anti-mOR37 antibody specifically recognized a single polypeptide band with an apparent molecular weight of $\sim 35 \mathrm{kDa}$ (Fig. 3, lane 1); this size is consistent with the predicted molecular mass on the basis of sequence data for the mOR37 receptors. After preabsorption of the antibody to the corresponding antigenic peptide, or without primary antibody, no immunoreactivity was observed (Fig. 3, lanes 2 and 3). The antimOR256-17 antibody was not reactive on Western blots.

To provide more evidence that anti-mOR37 specifically recognized the corresponding receptor proteins, we analyzed whether cells expressing the distinct $m O R 37$ subtypes were specifically labeled by this newly generated antibody. For this purpose we used our previously generated transgenic mouse lines, in which either $\beta$-galactosidase or GFP is coexpressed in those OSNs that express a particular mOR37 subtype (Strotmann et al., 2000). For three different receptor subtypes (mOR37A, $-B$, and $-C)$, double immunohistochemical labeling experiments were performed visualizing $\beta$-galactosidase (or GFP) and the anti- 

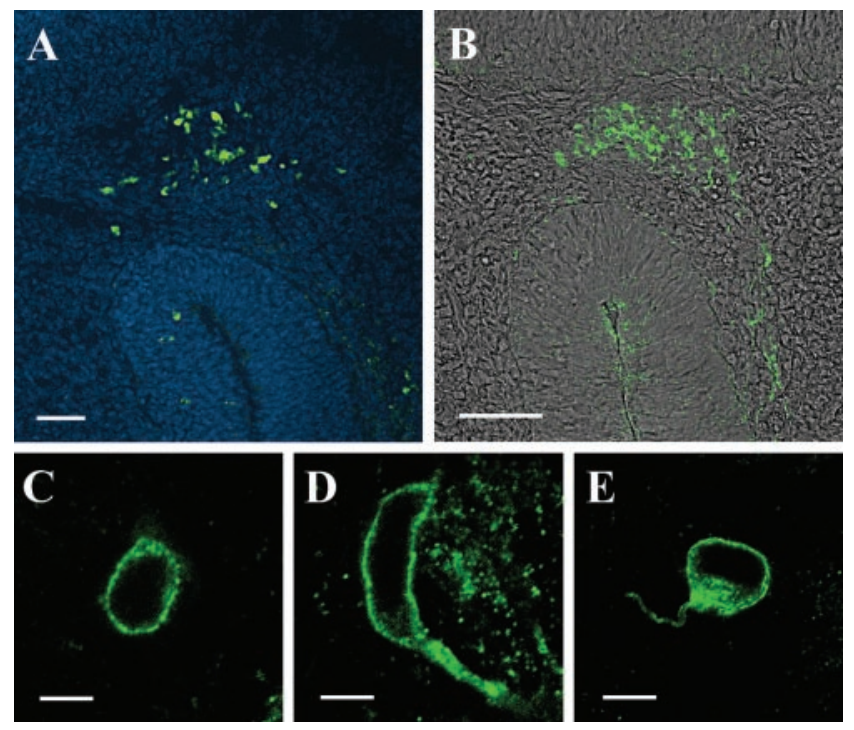

Figure 5. $A$, Cross section through the head of an E12.25 mouse embryo probed with an m0R256 -17-specific, biotin-labeled antisense riboprobe. A group of extraepithelial receptorexpressing cells is located in the cribriform mesenchyme between the developing olfactory epithelium and the presumptive olfactory bulb. The section was counterstained with DAPI. Scale bar, $50 \mu \mathrm{m} . B$, Cross section through the head of an E12.25 mouse embryo probed with the anti-m0R256-17 antibody. A group of immunoreactive cells located in the same position as those cells detected by in situ hybridization $(A)$ is visible. The immunofluorescence picture is overlayed with the transmission channel image. Scale bar, $50 \mu \mathrm{m}$. C, A $1 \mu \mathrm{m}$ confocal section through an extraepithelial cell stained with the anti-m0R256-17 antibody. The cell exhibits a typical ring-shaped fluorescence. Scale bar, $5 \mu \mathrm{m}$. D, E, Confocal images $(1 \mu \mathrm{m})$ of representative extraepithelial cells immunoreactive to anti-m0R256 -17; both cells display a short process being immunopositive. Scale bars, $5 \mu \mathrm{m}$.

mOR37 antigen, simultaneously. As can be seen in Figure $4 A-C$, in specimens from all three mouse lines a few distinct cells are labeled because of the transgenic marker. In the second panel $\left(A^{\prime}\right.$, $\left.B^{\prime}, C^{\prime}\right)$, labeling with the anti-mOR37 antibody is visualized, indicating that in each specimen more cells are immunoreactive, consistent with the fact that because of the antigenic peptide all mOR37 subtypes should be recognized by the antibody. As indicated by the overlay of the two fluorescent colors (third panel, $A^{\prime \prime}$, $\left.B^{\prime \prime}, C^{\prime \prime}\right)$, it is evident that each cell expressing an $m O R 37$ receptor type is specifically stained by the antibody. These results emphasize the specificity of the anti-mOR37 antibody.

For the receptor type $m O R 256-17$ we have recently demonstrated that mRNA is not only detectable in cells of the olfactory epithelium, but, during distinct developmental stages, also in cells positioned within the cribriform mesenchyme, i.e., between the olfactory epithelium and the developing olfactory bulb (Schwarzenbacher et al., 2004). To evaluate whether the antimOR256-17 antibody may also stain these "extraepithelial" cells, comparative labeling procedures were performed. In coronal sections through the developing olfactory system at embryonic day 12.25 , several groups of cells could be visualized in the cribriform mesenchyme by in situ hybridization with an mOR256-17specific antisense riboprobe (Fig. 5A). Incubation of corresponding sections with the $\alpha$-mOR256-17 antibody visualized immunoreactive cells at exactly the same position in the mesenchyme (Fig. 5B). In both approaches a similar number of cells was labeled. At higher magnification, the immunoreactive cells exhibited a characteristic ring-shaped fluorescence (Fig. 5C), indicative of a membrane localization of the corresponding antigen. Many cells were seen with short immunopositive processes ex- tending from the soma; the processes were typically quite thick (Fig. 5D), but in some cases rather slender processes were observed (Fig. 5E). These results exactly reflected the features for the extraepithelial cells expressing mOR256-17, as previously obtained by analysis of olfactory marker protein-GFP transgenic animals (Schwarzenbacher et al., 2004). These observations further support the view that the anti-mOR256-17 antibody specifically recognized the mOR256-17 protein.

Altogether, these results provided substantial evidence that the newly generated antibodies specifically recognized the respective OR proteins, therefore they may serve as a tool to approach the question, whether OR proteins are present in the axon terminals of OSNs in the olfactory bulb, as has been hypothesized for a long time. In a first set of experiments, we have therefore used the anti-mOR256-17 antibody on series of sections through the bulb. On distinct coronal sections through the bulb, immunoreactivity was indeed detectable at defined positions. Figure $6 \mathrm{~A}$ shows one representative example; on this section through the left and right bulbs, a strongly fluorescent glomerulus was detectable in the dorsolateral region in each bulb; the glomeruli were thus positioned bilaterally symmetric in the two bulbs. On sections through the more posterior region of the bulb, a second pair of glomeruli was identifiable, again positioned bilaterally symmetric in the two bulbs, this time in the medial domain of the bulb (Fig. 6B). From this view it is, however, not unequivocally clear whether the protein was located in the axons of mOR25617-expressing OSNs projecting into the bulb, or alternatively on processes of olfactory bulb neurons. Therefore, the sections were examined at higher magnification. In all cases, a strong immunoreactivity was detectable in axon fascicles entering the glomeruli from the outer nerve layer (Fig. $6 C-F$ ). In control experiments using peptide-preincubated anti-mOR256-17 on adjacent sections, all immunoreactivity was completely abolished (Fig. 6G). These observations provided strong evidence that the immunoreactivity detected within individual glomeruli reflects the presence of mOR256-17 receptor protein in sensory axon terminals. Similar images were recently obtained by Barnea et al. (2004) using antibodies against epitopes of the receptor type MOR28.

To approach the question whether OR proteins may in general be present in the axons of OSNs expressing that particular receptor gene, we next used the anti-mOR37 antibody on serial sections through the olfactory bulb. Immunoreactivity was indeed observed on distinct sections, this time in the ventral region of the bulb (Fig. 7A). Higher magnification (Fig. 7B) demonstrated that not only a single glomerulus was immunoreactive on this section, but two distinct glomeruli which, in contrast to those two identified by anti-mOR256-17, were positioned next to each other. On adjacent sections, two additional glomeruli positioned in close neighborhood were immunoreactive (data not shown). The position and number of these anti-mOR37-immunoreactive glomeruli in the ventral domain of the bulb indicated that they indeed represented the target sites for the mOR37-expressing neuron populations, because these have previously been identified in exactly this domain of the bulb of transgenic mice (Strotmann et al., 2000). To unequivocally match the anti-mOR37immunoreactive glomeruli with the glomeruli targeted by the mOR37-expressing cells, the staining experiments were performed using our transgenic mouse lines. Coimmunostaining using either intrinsic GFP fluorescence or antibodies against $\beta$-galactosidase together with anti-mOR37 revealed that in all cases $(n=8)$ one of the several anti-mOR37-immunoreactive glomeruli was costained by the transgenic marker (Fig. $7 F-H$ ), demonstrating that this particu- 

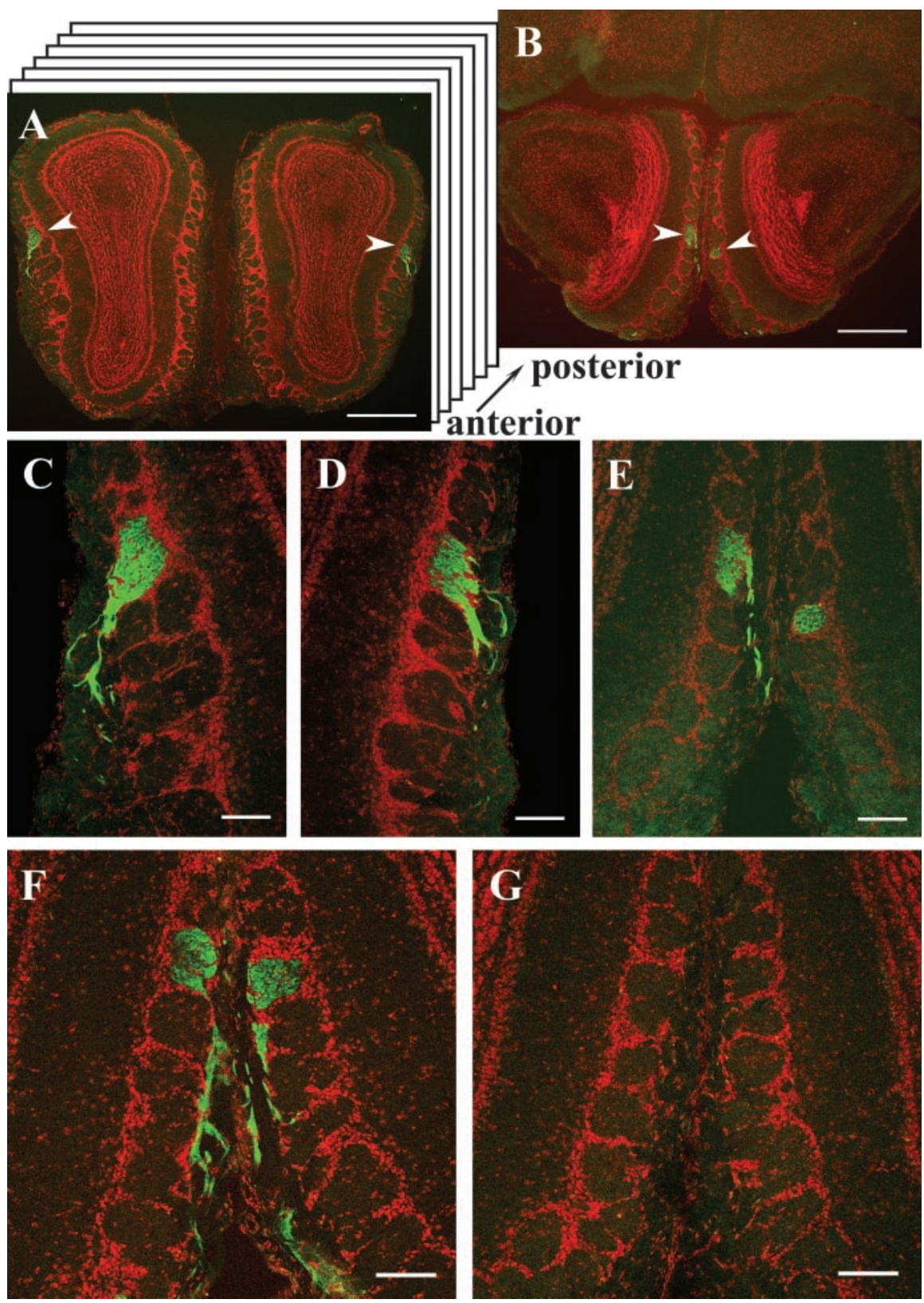

Figure 6. A, Cross section through the olfactory bulbs of a C57/BL6 wild-type mouse probed with the anti-m0R256-17 antibody. A strongly immunoreactive glomerulus is visualized in both bulbs in the dorsolateral domain (arrowheads). Counterstaining was performed with propidium iodide. Scale bar, $500 \mu \mathrm{m}$. B, Cross section through the bulbs shown in $A$ from a more posterior region. A second pair of immunoreactive glomeruli (arrowheads) is visible in the medial region of both bulbs. Scale bar, $500 \mu \mathrm{m}$. C, Higher magnification of the glomerulus from the left bulb in $A$ showing immunoreactive fibers in the outer nerve layer of the bulb entering the glomerulus. Scale bar, $100 \mu \mathrm{m}$. D, Higher magnification of the glomerulus from the right bulb in $A$ showing immunoreactive fibers entering the glomerulus from the outer nerve layer. Scale bar, $100 \mu \mathrm{m}$. E, High-power photomicrograph of the pair of medial glomeruli located in the posterior region of the bulb. Immunoreactive fibers are only visible in the outer nerve layer of the left bulb; because of a slight skewing of the bulbs, the medial glomerulus in the right bulb is slightly displaced, and no fibers are visible on this section. Scale bar, $100 \mu \mathrm{m}$. F, Cross section with the pair of medial anti-m0R256 -17immunoreactive glomeruli and incoming fibers located in the posterior region of the bulbs. Scale bar, $100 \mu \mathrm{m}$. G, Adjacent cross section to F probed with peptide-preabsorbed anti-m0R265-17 antibody; no immunoreactivity is detectable. Scale bar, $100 \mu \mathrm{m}$.

lar glomerulus was specifically innervated by OSNs expressing a distinct $m O R 37$-subtype.

\section{Discussion}

The results of the present study indicate that our peptide-derived antibodies specifically recognize distinct OR proteins, thus representing novel tools not only for characterizing the OR protein, but also for visualizing the distribution of OR proteins in the various compartments of ORNs. In previous studies, peptidebased anti-OR-antibodies have allowed a specific labeling of the ciliary layer and some cell somata (Koshimoto et al., 1992, 1994; Krieger et al., 1994), as well as the membrane of olfactory cilia (Menco et al., 1997), and only a recent report has demonstrated labeling of glomeruli (Barnea et al., 2004). The newly generated antibodies and the greatly improved microscopic techniques have opened avenues to visualize OR-immunoreactive structures in much greater detail. The whole-mount preparations allowed to localize and to quantify the immunoreactive knobs on the surface of the epithelium; moreover, this approach enabled to visualize the complex network of cilia extending from the dendritic knob. An unexpected feature was the distinct labeling of the dendritic knob. The ring-like distribution of immunoreactivity suggests a local sorting of the receptor protein; ultrastructural analyses may provide some further insight. The strong immunoreactivity in the cell bodies, especially in the supranuclear compartment, which most probably represents the ER-Golgi complex, suggests a high rate of receptor synthesis. This view is in line with strong immunoreactivity also in the dendrites; interestingly, in this cellular compartment a dot-like labeling was predominant (Fig. 2). It will be of a great interest to evaluate by ultrastructural analyses, whether these dots are vesicles en route between soma and cilia. Thus, the antibodies may allow to begin investigations concerning the processing, sorting, and targeting of OR proteins in OSNs. These aspects are of particular relevance in view of the findings that OR proteins not only are located in the dendrite-cilia compartment, but also in the axonal process.

The finding that strong receptor immunoreactivity is also present in axonal processes and nerve terminals in the glomerular neuropil confirms a recent observation for a different receptor type (Barnea et al., 2004) and is of particular importance with great implications for the molecular mechanisms underlying the wiring of the olfactory system. The data demonstrate the presence of OR proteins in the axonal processes as previously hypothesized based on the receptor-specific targeting of olfactory axons in the bulb. It has been proposed that OR proteins may contribute to a precise targeting of outgrowing axons. Interestingly, our present data indicate that not only a few outgrowing axons are immunoreactive, but rather the entire subpopulation of fibers seems to be labeled. Furthermore, in addition to the axon terminals in the glomeruli, labeled fibers could 
be followed over a long distance (Fig. 6). This staining pattern very much resembled those obtained in transgenic mice, in which all axons from an OSN population expressing a given OR gene are specifically labeled by coexpression of a histological marker (Mombaerts et al., 1996; Wang et al., 1998; Strotmann et al., 2000; Zheng et al., 2000; Potter et al., 2001). These results imply that the OR protein is permanently present in the axon, even when the targeting process is already finished.

In an alternative hypothesis it has been proposed that OR proteins in the axon membrane might aid in a precise fasciculation of alike olfactory axons (Mombaerts, 2001; Treloar et al., 2002). Although the axons from OSNs expressing a distinct OR type eventually all project to their common glomerulus, they exit the epithelium in bundles that supposedly consist of fibers from cells of many different receptor specificities (Royal and Key, 1999; St John et al., 2002). After contact with the bulb, these bundles defasciculate, and axons from the same receptor-specific subpopulation are reassorted in bundles that finally converge to form a glomerulus (Treloar et al., 2002). This "self"association is considered as an important step in the process of forming the topographic projection maps in the bulb. Based on the localization of the OR immunoreactivity, it seems possible that the OR protein is indeed involved in this process. The underlying molecular mechanisms are totally elusive; in fact, such a role in cell recognition has not been demonstrated for any of the multiple G-protein-coupled receptors. However, a very recent study demonstrated that substituting the coding region of an OR gene by the coding region for a $\beta$-adrenergic receptor led to OSNs that project to a common glomerulus (Feinstein et al., 2004). In view of a possible role of OR proteins in axon fasciculation in the outer nerve layer of the olfactory bulb, it is interesting to note that the immunofluorescence of nerve fibers was particularly strong within the bulb, whereas staining of the nerve fibers was not as well detectable in regions outside to bulb. This could be attributable to the fact that after crossing the cribriform plate and resorting in the outer nerve layer, bundles may now indeed comprise mostly fibers of the same receptor type, thus causing a bright fluorescence of the bundles. However, it is also conceivable, that only after axons have reached this sorting zone, the OR proteins are inserted into the axonal membrane; thereby, the epitope may become more accessible for the antibody.
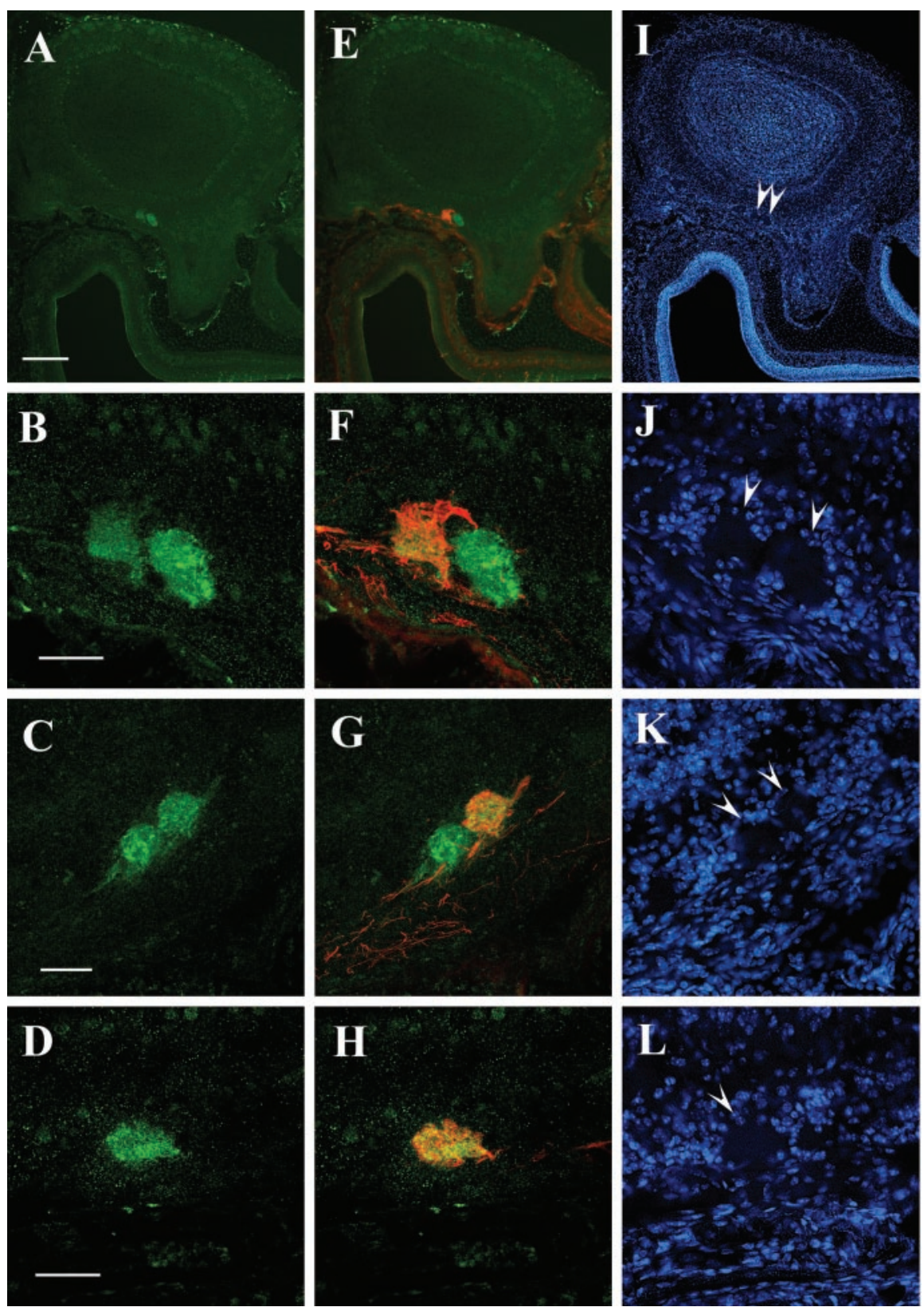

Figure 7. A, Cross section through the olfactory bulb of an m0R37C-lacZ transgenic mouse probed with the anti-m0R37 antibody. Immunoreactivity is detectable in a small spot located the ventral region of the bulb. Scale bar, $200 \mu \mathrm{m}$. B, High magnification of the ventral domain of the bulb shown in $A$, visualizing the anti-mOR37-immunoreactive structures; two distinct glomeruli are stained located next to each other. Scale bar, $50 \mu \mathrm{m}$. C, High magnification of the ventral domain of the bulb from an mOR37B-lacZ transgenic mouse, visualizing the anti-m0R37-immunoreactive structures; two distinct glomeruli that are located next to each other are stained on this section. Scale bar, $50 \mu \mathrm{m}$. D, High magnification of the ventral domain of the bulb from an mOR37A-GFP transgenic mouse, visualizing the anti-m0R37 immunoreactive structure; one glomerulus is stained on this section. The glomerulus is visualized by an Alexa-568 conjugated antibody, which is presented in green color. Scale bar, $50 \mu \mathrm{m}$. $E$, Overlay of the picture shown in $A$ with anti- $\beta$-galactosidase immunostaining demonstrating the position of axon terminals from OSNs expressing $m O R 37 C$; immunofluorescence is detectable in the ventral domain of the bulb, colocalized with the antim0R37 immunoreactivity. $F$, Overlay of the picture shown in $B$ with anti- $\beta$-galactosidase immunostaining for m0R37C-lacZ; one of the two glomeruli on this section immunoreactive for anti-mOR37 contains fibers from mOR37C-expressing OSNs. G, Overlay of the picture shown in $C$ with anti- $\beta$-galactosidase immunostaining for $\mathrm{mOR} 37 \mathrm{~B}$-lacZ; one of the two glomeruli on this section immunoreactive for anti-mOR37 contains fibers from $m 0 R 37 B$-expressing $0 S N s$. $H$, Overlay of the picture shown in $D$ with intrinsic GFP fluorescence of mOR37A-GFP containing fibers; this glomerulus immunoreactive for anti-mOR37A also contains fibers from mOR37A-expressing OSNs. I, DAPI counterstaining of the section shown in $A$ and $E$. Arrowheads indicate the positions of immunoreactive glomeruli. J, DAPI counterstaining of the section shown in $B$ and $F$. Arrowheads indicate the positions of immunoreactive glomeruli. $K$, DAPI counterstaining of the section shown in $C$ and $G$. Arrowheads indicate the positions of immunoreactive glomeruli. L, DAPI counterstaining of the section shown in $D$ and $H$. Arrowhead indicates the position of the immunoreactive glomerulus. 
The precise localization of the OR proteins in the axonal process can only be solved by ultrastructural analyses at the EM level.

In summary, the data presented in this study demonstrate that OR proteins are present in various subcellular compartments of the OSN. Most notable is the localization in the axonal processes and nerve terminals. This strongly supports the hypothesis that ORs may contribute in the molecular processes underlying the precise fasciculation and targeting of olfactory axons.

\section{References}

Anholt RRH, Aebi U, Snyder SH (1986) A partially purified preparation of isolated chemosensory cilia from the olfactory epithelium of the bullfrog, Rana catesbeiana. J Neurosci 6:1962-1969.

Barnea G, O’Donnell S, Mancia F, Sun X, Nemes A, Mendelson M, Axel R (2004) Odorant receptors on axon termini in the brain. Science 304:1468.

Bozza TC, Mombaerts P (2001) Olfactory coding: revealing intrinsic representations of odors. Curr Biol 11:R687-R690.

Bozza T, Feinstein P, Zheng C, Mombaerts P (2002) Odorant receptor expression defines functional units in the mouse olfactory system. J Neurosci 22:3033-3043.

Bradford MM (1976) A rapid and sensitive method for the quantitation of microquantites of protein utilizing the principle of protein-dye binding. Anal Biochem 65:248-254.

Buck LB (1996) Information coding in the vertebrate olfactory system. Annu Rev Neurosci 19:517-544.

Buck LB (2000) The molecular architecture of odor and pheromone sensing in mammals. Cell 100:61-618.

Feinstein P, Bozza T, Rodriguez I, Vassalli A, Mombaerts P (2004) Axon guidance of mouse olfactory sensory neurons by odorant receptors and the beta2 adrenergic receptor. Cell 117:833-846.

Hoppe R, Weimer M, Beck A, Breer H, Strotmann J (2000) Sequence analyses of the olfactory receptor gene cluster mOR 37 on mouse chromosome 4. Genomics 66:284-295.

Kaluza JF, Gussing F, Bohm S, Breer H, Strotmann J (2004) Olfactory receptors in the mouse septal organ. J Neurosci Res 76:442-452.

Koshimoto H, Katoh K, Yoshihara Y, Mori K (1992) Distribution of putative odour receptor proteins in olfactory epithelium. NeuroReport 3:521-523.

Koshimoto H, Katoh K, Yoshihara Y, Nemoto Y, Mori K (1994) Immunohistochemical demonstration of embryonic expression of an odor receptor protein and its zonal distribution in the rat olfactory epithelium. Neurosci Lett 169:73-76.

Krieger J, Schleicher S, Strotmann J, Wanner I, Boekhoff I, Raming K, De Geus P, Breer H (1994) Probing olfactory receptors with sequencespecific antibodies. Eur J Biochem 219:829-835.

Lewcock JW, Reed RR (2004) A feedback mechanism regulates monoallelic odorant receptor expression. Proc Natl Acad Sci USA 101:1069-1074.

Menco BPM, Cunningham AM, Qasba P, Levy N, Reed RR (1997) Putative odour receptor localize in cilia of olfactory receptor cells in rat and mouse: a freeze-substitution ultrastructural study. J Neurocytol 26:691-706.
Mombaerts P (2001) How smell develops. Nat Neurosci 4 [Suppl]:1192-1198.

Mombaerts P (2004) Genes and ligands for odorant, vomeronasal and taste receptors. Nat Rev Neurosci 5:263-278.

Mombaerts P, Wang F, Dulac C, Chao SK, Nemes A, Mendelsohn M, Edmondson J, Axel R (1996) Visualizing an olfactory sensory map. Cell 87:675-686.

Mori K, Nagao H, Yoshihara Y (1999) The olfactory bulb: coding and processing of odor molecule information. Science 286:711-715.

Potter SM, Zheng C, Koos DS, Feinstein P, Fraser SE, Mombaerts P (2001) Structure and emergence of specific olfactory glomeruli in the mouse. J Neurosci 21:9713-9723.

Ressler KJ, Sullivan SL, Buck LB (1993) A zonal organization of odorant receptor gene expression in the olfactory epithelium. Cell 73:597-609.

Ressler KJ, Sullivan SL, Buck LB (1994) Information coding in the olfactory system: evidence for a stereotyped and highly organized epitope map in the olfactory bulb. Cell 79:1245-1255.

Royal SJ, Key B (1999) Development of P2 olfactory glomeruli in P2internal ribosome entry site-tau-LacZ transgenic mice. J Neurosci 19:9856-9864.

Schwarzenbacher K, Fleischer J, Breer H, Conzelmann S (2004) Expression of olfactory receptors in the cribriform mesenchyme during prenatal development. Gene Expr Patterns 4:543-552.

Serizawa S, Miyamichi K, Nakatani H, Suzuki M, Saito M, Yoshihara Y, Sakano H (2003) Negative feedback regulation ensures the one receptor-one olfactory neuron rule in mouse. Science 302:2088-2094.

St. John JA, Clarris HJ, Key B (2002) Multiple axon guidance cues establish the olfactory topographic map: how do these cues interact? Int J Dev Biol 46:639-647.

Strotmann J, Wanner I, Krieger J, Raming K, Breer H (1992) Expression of odorant receptors in spatially restricted subsets of chemosensory neurones. NeuroReport 3:1053-1056.

Strotmann J, Wanner I, Helfrich T, Beck A, Breer H (1994a) Rostro-caudal patterning of receptor-expressing olfactory neurones in the rat nasal cavity. Cell Tissue Res 278:11-20.

Strotmann J, Wanner I, Helfrich T, Beck A, Meinken C, Kubick S, Breer H (1994b) Olfactory neurones expressing distinct odorant receptor subtypes are spatially segregated in the nasal neuroepithelium. Cell Tissue Res 276:429-438.

Strotmann J, Conzelmann S, Beck A, Feinstein P, Breer H, Mombaerts P (2000) Local permutations in the glomerular array of the mouse olfactory bulb. J Neurosci 20:6927-6938.

Treloar HB, Feinstein P, Mombaerts P, Greer CA (2002) Specificity of glomerular targeting by olfactory sensory axons. J Neurosci 22:2469-2477.

Vassar R, Ngai J, Axel R (1993) Spatial segregation of odorant receptor expression in the mammalian olfactory epithelium. Cell 74:309-318.

Vassar R, Chao SK, Sitcheran R, Nunez JM, Vosshall LB, Axel R (1994) Topographic organization of sensory projections to the olfactory bulb. Cell 79:981-991.

Wang F, Nemes A, Mendelsohn M, Axel R (1998) Odorant receptors govern the formation of a precise topographic map. Cell 93:47-60.

Zheng C, Feinstein P, Bozza T, Rodriguez I, Mombaerts P (2000) Peripheral olfactory projections are differentially affected in mice deficient in a cyclic nucleotide-gated channel subunit. Neuron 26:81-91. 